\title{
Fibre laser piercing of mild steel -The effects of power intensity, gas type and pressure
}

\author{
M. Hashemzadeh ${ }^{1}$, J. Powell ${ }^{2}$, K.T. Voisey ${ }^{1 *}$
}

1. Materials, Mechanics and Structures Research Division, Faculty of Engineering, University of Nottingham, University Park, Nottingham NG7 2RD, UK

2. Dept. of Engineering Sciences and Mathematics, Lulea University of Technology. SE-971 87 Lulea, Sweden.

*corresponding author, katy.voisey@nottingham.ac.uk, +44(0)1159514139

\begin{abstract}
Laser piercing is used to generate a starting point for laser cutting. The pierced hole is normally larger than the kerf width, which means that it cannot lie on the cut line. An experimental program investigating the piercing process as a function of laser and assist gas parameters is presented. An Nd:YAG fibre laser with a maximum power of $2 \mathrm{~kW}$ was used in continuous wave mode to pierce holes in $2 \mathrm{~mm}$ thick mild steel. Oxygen and nitrogen were used as assist gases, with pressures ranging from 0.3 to 12 bar. The sizes, geometries and piercing time of the holes produced have been analysed. The pierced hole size decreases with increasing gas pressure and increasing laser power. Oxygen assist gas produced larger diameter holes than nitrogen. A new technique is presented which produces pierced holes no larger than the kerf with and would allow the pierced hole to lie on the cut line of the finished product - allowing better material usage. This uses an inclined jet of nitrogen when piercing prior to oxygen assisted cutting.
\end{abstract}

Keywords Laser piercing, laser cutting, mild steel, fibre laser, fiber laser

\section{Introduction}

Laser cutting of sheet metal is widely used in industry. The process basically consists of the laser melting material which is then expelled through the bottom of the cut kerf by the action of a gas jet. Oxygen is often employed as the assist gas when cutting mild steel as it adds energy to the process via the exothermic oxidation of iron.

Cuts do not generally start from the free edge of a sheet and so a hole needs to be pierced from which the laser cut can begin. This is usually simply done by holding the laser beam stationary at the start of the cut until a through-hole is pierced. Subsequent motion of the laser with respect to this point then generates the cut. It is the initial piercing operation that is of interest to the current work.

As illustrated in

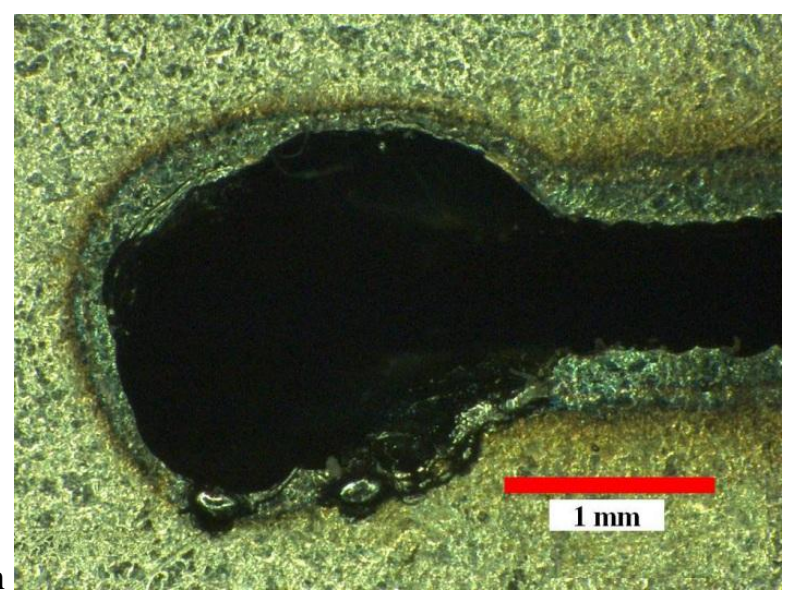


Figure 1, the diameter of the initial pierced hole generally exceeds the kerf width of the cut. It is therefore normal practice for the initial pierced hole site to be positioned off of the final cut edge, as shown in

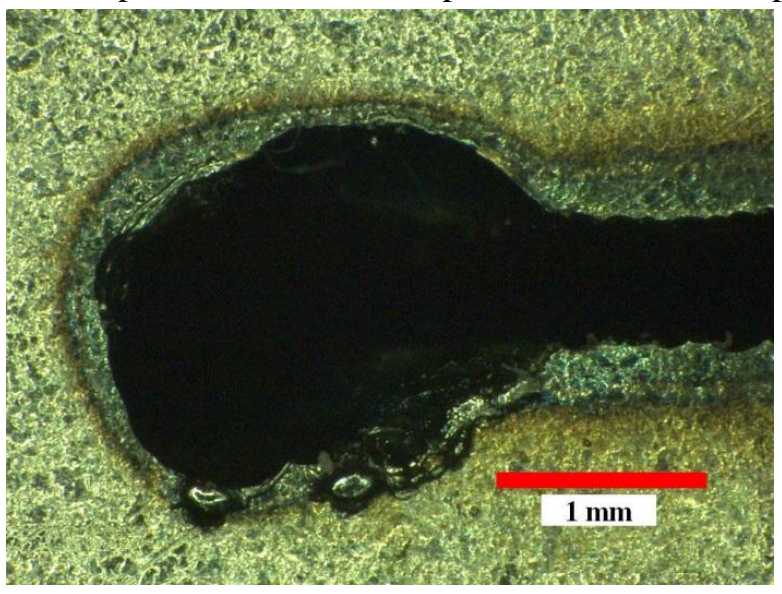

Figure 1- A pierced hole at the start of a laser cut in $2 \mathrm{~mm}$ thick mild steel using $1000 \mathrm{~W}, 2$ bar oxygen. The piercing hole is usually considerably wider than the kerf width (the kerf is shown here on the right hand side of the figure).

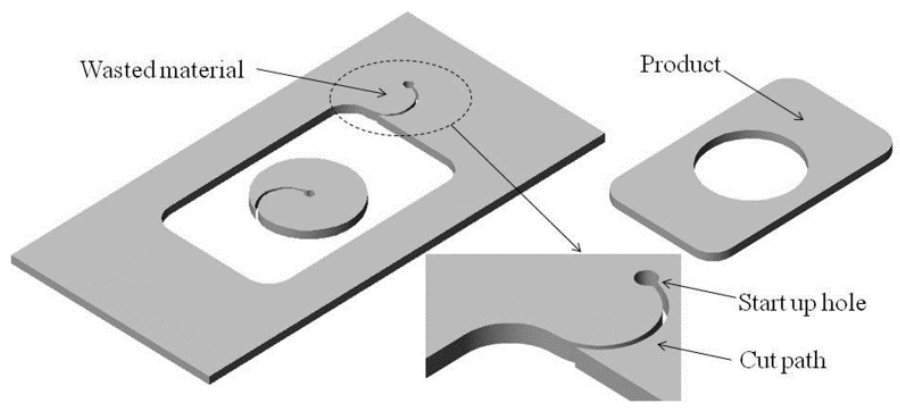

Figure 2. This optimises the quality of the cut but also results in some material wastage. The ideal case would be for the diameter of the initial pierced hole to match the kerf width. There would then be no need for the pierced hole to lie off of the final cut line which would result in two benefits; a. cut parts could be placed closer together on the sheet, saving material, $b$. the cut line from the pierce hole to the required profile would not be necessary, reducing process time.

As piercing is the initial step of the cutting process it might be assumed that the physics of piercing would be similar to that of cutting - but in fact the two phenomena are quite different. The main difference is the direction of fluid flow of the melt created - towards the laser in the case of piercing, and away from the laser during cutting.

Laser piercing has several similarities to, but also some important differences from, laser drilling. Both methods generate a hole by ejecting molten material back through the hole entrance until breakthrough (Figure 3), after which molten material can exit through the bottom of the hole [1]. Some vaporisation occurs, and the recoil pressure generated can aid expulsion of molten material. Both processes usually result in resolidified material lining the hole [1] and the generation of heat affected zones [2] and surface spatter [3]. However, laser drilling is usually carried out using pulsed lasers, whereas continuous wave irradiation is often used for piercing. Laser drilling is generally done to generate functional holes with specific high tolerance geometries and dimensions, there is therefore a considerable amount of interest in quality control and reproducibility [4]. In piercing only the hole diameter and time of penetration are of practical interest. 
A significant amount of work has been done on understanding how process parameters affect laser drilling [5-10]. The laser drilling that is closest to the laser piercing work here is laser drilling of metallic materials several mm in thickness using Nd:YAG lasers with pulse lengths of the order of milliseconds and pulse energies of a few joules. In such laser drilling material removal occurs primarily via melt ejection $[1,3,5-$ 11]. It is well known that assist gas pressure affects hole shape and dimensions [11], with an increase in assist gas pressure normally enhancing the melt ejection process, decreasing the time required for drilling. As for laser cutting [12], the use of oxygen as an assist gas enhances the drilling process since the exothermic oxidation reaction acts as an additional heat source. For the conditions and laser wavelength used in this work laser-plasma effects are not expected to be significant [13].

The piercing time and hole diameter can be affected by a number of process parameters including laser wavelength, power, power modulation and assist gas type and pressure [14]. This paper presents the results of a detailed systematic study of piercing $2 \mathrm{~mm}$ thick mild steel sheet using a fibre laser in its continuous wave mode and oxygen or nitrogen as the assist gas. In piercing, the presence of oxygen in the melting zone generates additional heat from the exothermic oxidation reaction and also produces a relatively low viscosity oxidised melt $[12,15]$.

Whilst there is extensive published literature on laser cutting and laser drilling, there is little on the laser piercing process. This work aims to investigate the piercing process as a function of irradiation time, assist gas type and pressure. The ultimate objective is to use the understanding thus gained in order to minimise the dimensions of the pierce hole, ideally making it no larger than the kerf width, thereby decreasing material wastage.

\section{Experimental method}

\subsection{Material}

$2 \mathrm{~mm}$ thick cold rolled mild steel was utilised in this work. The chemical composition, as determined by spark emission, is given in Table 1.

\subsection{Laser}

An IPG YLR-2000 multimode Nd:YAG $2 \mathrm{~kW}, 1.06 \mu \mathrm{m}$ wavelength fibre laser was used in the continuous wave mode. Powers in the range of $600 \mathrm{~W}$ to $1400 \mathrm{~W}$ were used. The laser beam was delivered into the cutting head by a $200 \mu \mathrm{m}$ diameter optical fibre. This was focussed by a $120 \mathrm{~mm}$ focal length lens into a spot with a diameter of $206 \mu \mathrm{m}$. Throughout the work the focal position was on the top surface of the sample, the focus did not move with respect to its original position as the hole progressed. A $1 \mathrm{~mm}$ diameter nozzle was used to deliver the assist gas coaxially to the laser beam, the standoff distance between nozzle and sample surface was $1 \mathrm{~mm}$.

Nitrogen and oxygen were used as assist gases over a range of pressures from 0.3 bar to 12 bar.

Table 2 details the parameters used. It should be noted that the laser was only on for the times stated, however the assist gas continued to flow for some time after the laser had been turned off. For each parameter setting five holes were pierced and the results presented are the average values.

\subsection{Sample examination}

The pierced sheets were sectioned to observe the partially penetrating and full penetration pierce holes. Every sample included a set of five adjacent holes produced under identical process conditions and was mounted in conductive bakelite. In order to measure the hole dimensions (depth, diameter) and also observe the heat affected zone (HAZ) and re-solidified zone (RSZ), each sample was sectioned, ground and etched with nital $2 \%$. 
A special grinding polishing technique was employed to make sure that the deepest, central plane of the piercing holes were examined because off-centre sections would give inaccurate results. The samples were ground at a slight angle to the line of holes (Figure 4). Once the holes started to be visible in the ground plane a series of images were taken using an optical microscope equipped with a digital camera after each grinding increment. In the sequence of images each hole will get larger as the mid plane is approached, then smaller as it is passed. The grinding process was stopped when the central hole was sectioned across its centre line.

The optical micrographs of the mid plane of the pierced holes were imported into AutoCAD, where a spline tool was used to draw outlines of the edge of the hole, the re-solidified zone and HAZ. These, directly traced, outlines are presented in the hole growth maps in the results sections. Figure 6 shows the optical micrographs of pierced holes and the corresponding hole growth maps produced. By using the region, revolve and subtract tools of AutoCAD the volume of revolution of the holes was generated and the numerical value of the relevant volumes determined. This process assumes that the cross-section used is fully representative of the hole, i.e. that the hole is cylindrically symmetrical about its axis. The wealth of data generated from the grinding process indicated that this is a reasonable approximation in most cases.

\section{Results and discussion}

\subsection{The piercing mechanism}

Figure 5 explains our use of the terms 'melted' and 'ejected' in the following discussion. 'Melted refers to the total volume of material melted (i.e. the melt remaining in the hole and the melt ejected). 'Ejected' refers to the melt removed from the hole by the combined action of the laser and the gas jet (the total volume of voids in the melt).

The following hole growth maps show the shape and dimensions observed from the cross-sectional images obtained after laser irradiation for the various times stated, such as those shown in fig 6a. It must be noted that they cannot simply be regarded as snapshots showing the situations at the stated times, instead they show the end result of different irradiation times. Several processes can occur after the laser is switched off, these include continued melt flow, heat transfer from the molten material within the hole to adjacent material, oxidation, and the possibility of the collapse of melt back into the hole.

\subsection{Piercing with nitrogen}

Figure $6 a \& b$ shows that, as would be expected, the depth of the melted hole increases with laser interaction time. For these conditions (1000W, 2 bar) sporadic penetration happens at approximately $20 \mathrm{~ms}$ of irradiation and full penetration is reliably achieved at $24 \mathrm{~ms}$. Figure 7 demonstrates that, if the assist gas pressure is decreased then penetration time can increase. Figure 8 explains this, showing that although the amount of melt generated is solely dependent on interaction time for a given set of laser parameters, the rate of material ejection from the cut zone increases dramatically as the gas pressure is increased from 0.3 bar to 2.0 bar. It is also clear from Figures $7 \& 8$ that if the gas pressure is too low to remove the melt at the same rate at which it is generated, then hot melt is retained in the hole. This hot melt then conducts heat laterally, which causes an additional melting and broadening of the penetration hole.

Figure 9 demonstrates that the penetration mechanism remains the same at higher power but takes place more rapidly. The subject of piercing time will be discussed in section $3 \mathrm{~b}$.

\subsection{Piercing with Oxygen}

Figures 10-12 show the same trends exist for piercing with oxygen as they do in the case of nitrogen. Very low assist gas pressure is seen to be insufficient for melt ejection leading to slower penetration and broader pierced holes and piercing times decrease as the power increases. 
Figure 13 demonstrates that, at the same laser power and gas pressure, oxygen promotes more melting and more melt ejection as a function of time than nitrogen does. These two points can be explained as follows;

The partially oxidised melt produced has a lower viscosity than the unoxidised melt produced when nitrogen is employed [16]. This lower viscosity melt can be more easily ejected.

The molten oxidised liquid generates heat as it oxidises - and therefore melts more of its surrounding material $[17,18]$. This exothermic reaction continues for a short time even after the laser is turned off.

The second point above also explains the broader entrance seen in Figure 10 for the $10 \mathrm{~ms}$ hole compared to the 12 and $14 \mathrm{~ms}$ holes generated when piercing with 2 bar oxygen. The $10 \mathrm{~ms}$ hole is a blind hole in which oxidation of the retained melt continued after laser irradiation finished, thereby continuing to input heat into the material, broadening the melted region. This did not occur for the 12 and 14 ms holes as these are through holes so the majority of the melt exited the holes on breakthrough, significantly decreasing the effect of any on-going oxidation.

\subsection{Pierce times and hole diameters}

As mentioned in the introduction, the only two features of the piercing process which matter to the laser cutter are the pierce time and the piece hole maximum diameter. Smaller pierce times mean greater productivity and it could be of great benefit to reduce the pierce hole to approximately the same width as the cut kerf.

Previous work carried out with this laser to cut $2 \mathrm{~mm}$ mild steel with powers of $1000 \mathrm{~W}$ and $1500 \mathrm{~W}$ [15] has shown that the kerf widths for oxygen cutting are $0.48-0.56 \mathrm{~mm}$ for cutting speeds of $4000-$ $6000 \mathrm{~mm} \mathrm{~min}^{-1}$, and $0.30-0.41 \mathrm{~mm}$ for nitrogen cutting at speeds of $500-1000 \mathrm{~mm} \mathrm{~min}^{-1}$.

\subsubsection{Pierce breakthrough times}

Figure 14 gives the results of the piercing time measurements using various pressures and laser powers. Two points are clear from this figure;

Piercing time reduces as laser power increases.

Piercing time reduces with increasing gas pressure up to a certain threshold (approximately 6 bar in this case). Above this threshold pressure the piercing time is unaffected by further increases in pressure.

The observed reduction in time to breakthrough with increasing assist gas pressure is consistent with previously published work and is attributed to the higher pressure gas simply being more effective at removing melt. At the threshold pressure the melt is simply being removed as fast as it is being generated, hence further increase in pressure does not have any additional beneficial effect.

Figure 15 shows the results for piercing with oxygen. In this case piercing time continuously decreases with both laser power and gas pressure over the whole range shown here. It is possible that the decrease in piercing time with gas pressure plateaus out at higher pressure - but this result was not investigated further because high oxygen pressures result in poor quality cutting.

\subsubsection{Pierced hole diameters}

From an engineering point of view we are interested in the largest diameter of the conical piercing hole i.e. its diameter on the top surface of the metal. Figure 16 gives this measurement for nitrogen piercing as a function of laser power over a range of gas pressures. 
Figure 16 clearly shows that the upper surface hole diameter decreases gradually with both increasing laser power and increasing gas pressure. The reduction in diameter becomes less pronounced at higher pressures and, within the range of parameters investigated here, converges on a minimum of approximately $0.48 \mathrm{~mm}$ with maximum power of $2 \mathrm{~kW}$ in this case (Figure 16). This value is close to the upper end of the typical kerf width for this laser, cutting with nitrogen.

Figure 17 gives the results for piercing with oxygen and once again we can see a gradual reduction in upper hole diameter with laser power, but the results related to oxygen pressure show an increase in hole diameter with increasing pressure.

The growth of the hole diameter as a function of oxygen pressure can be explained in terms of the oxidation dynamics within the pierced hole. The increased pressure accelerates the oxidation reaction between oxygen and iron - also it can be reasonably assumed that the higher flow causes increased turbulence in the $\mathrm{Fe} / \mathrm{FeO}$ liquid which coats the hole surface. This turbulence reveals more liquid $\mathrm{Fe}$ to the oxygen and further oxidation is encouraged. Increased oxidation leads to further heat generation which results in more melting and the growth of the pierce hole diameter.

The results presented so far indicate that industrially realistic pressures and powers will not allow the pierced hole diameter to be less than the kerf width, so another approach is needed. Comparison of figs 16 and 17 indicates that nitrogen assisted piercing can produce pierce holes that are of the same dimensions as oxygen kerf widths. Taking this result as a starting point a 'proof of principle' experiment was carried out which involved piercing on the cut line with nitrogen and cutting with oxygen.

\subsection{Piercing with nitrogen cutting with oxygen}

In an innovative method, a combination of nitrogen laser pre-piercing and oxygen laser cutting can improve productivity and product yield from sheet material. This method involves piercing with an auxiliary nitrogen jet and then cutting with oxygen. This combination gives us a pierce hole whose diameter is similar to the kerf width. Figure 18 shows the practical set-up for these initial trials - with the auxiliary nozzle inclined at $40^{\circ}$ to the horizontal and a nitrogen supply pressure of 3 bar through a $2 \mathrm{~mm}$ diameter nozzle.

Figure 19 shows two holes pierced using the inclined nozzle at a laser power of $1500 \mathrm{~W}$ and an irradiation time of $20 \mathrm{~ms}$. Figure 20 shows the top view of a mild steel cut using oxygen which bisects this type of pierced hole. Thus it is clear that the use of this type of piercing could allow the piercing hole to lie on the cut line of the finished product.

As seen in Figure 19, the inclined nozzle results in a directional distribution of resolidified dross or spatter which adheres to the top surface. As expected, the dross is found to be directly opposite the position of the inclined nozzle. The cut made in Figure 20 was done without any prior removal of this surface spatter. It can be seen that the dross is removed by the cutting process, so by simply aligning the inclined nozzle with the final cut line the dross is removed.

Obviously this use of two gases - nitrogen to pierce, followed by oxygen to cut would need to be optimised in order to allow rapid pierce times. However there are many applications where the saving in material could be very worth-while - for example, when cutting interlocking parts with shared cut profiles, or when cutting rings within rings to produce sets of laser cut washers or shims.

\section{Conclusions}

- Piercing time reduces with both increasing laser power and assist gas pressure for both oxygen and nitrogen piercing. 
- Increasing laser power has a more significant effect: a $40 \%$ increase in power produces a $40-50 \%$ decrease in piercing time.

- The effect of increasing gas pressure is only significant at lower pressures, 2-4 bar, for oxygen piercing. For both gases, increasing pressure from 4 to 8 bar only decreases piercing time by about $10 \%$.

- Holes pierced with oxygen are considerably wider than those cut with nitrogen.

- A combination of piercing with nitrogen and cutting with oxygen can allow the piercing hole to be positioned on the cut line - which could be useful in maximising material usage for certain cut products. 


\section{Tables}

Table 1- Chemical composition of the mild steel (weight \%)

\begin{tabular}{|lllllllll|}
\hline $\mathrm{C}$ & $\mathrm{Si}$ & $\mathrm{Mn}$ & $\mathrm{P}$ & $\mathrm{S}$ & $\mathrm{Cr}$ & $\mathrm{Mo}$ & $\mathrm{Ni}$ & $\mathrm{Al}$ \\
\hline 0.0 & 0.0 & 0.1 & 0.0 & 0.0 & 0.0 & 0.0 & 0.0 & 0.0 \\
3 & 05 & 92 & 03 & 15 & 23 & 05 & 13 & 34 \\
\hline
\end{tabular}

Table 2- Piercing parameters used.

\begin{tabular}{|l|l|l|l|l|l|l|l|l|}
\hline \multicolumn{2}{|l|}{ Assist gas } & \multicolumn{6}{l|}{ Laser power / W } \\
\hline Gas & $\begin{array}{l}\text { Pressure } \\
\text { / bar }\end{array}$ & 600 & 800 & 1000 & 1200 & 1400 & 1700 & 2000 \\
\hline $\mathrm{N}_{2}$ & 0.3 & $\mathrm{X}$ & $\mathrm{X}$ & $\mathrm{X}$ & $\mathrm{X}$ & $\mathrm{X}$ & & \\
\hline $\mathrm{N}_{2}$ & 2 & & & $\mathrm{X}$ & $\mathrm{X}$ & $\mathrm{X}$ & $\mathrm{X}$ & $\mathrm{X}$ \\
\hline $\mathrm{N}_{2}$ & 3 & & & & & $\mathrm{X}$ & $\mathrm{X}$ & $\mathrm{X}$ \\
\hline $\mathrm{N}_{2}$ & 8 & & & & & $\mathrm{X}$ & $\mathrm{X}$ & $\mathrm{X}$ \\
\hline $\mathrm{N}_{2}$ & 12 & & & & & $\mathrm{X}$ & $\mathrm{X}$ & $\mathrm{X}$ \\
\hline $\mathrm{O}_{2}$ & 0.3 & $\mathrm{X}$ & $\mathrm{X}$ & $\mathrm{X}$ & $\mathrm{X}$ & $\mathrm{X}$ & $\mathrm{X}$ & $\mathrm{X}$ \\
\hline $\mathrm{O}_{2}$ & 2 & $\mathrm{X}$ & $\mathrm{X}$ & $\mathrm{X}$ & $\mathrm{X}$ & $\mathrm{X}$ & $\mathrm{X}$ & $\mathrm{X}$ \\
\hline $\mathrm{O}_{2}$ & 4 & & & & & $\mathrm{X}$ & $\mathrm{X}$ & $\mathrm{X}$ \\
\hline $\mathrm{O}_{2}$ & 8 & & & & & $\mathrm{X}$ & $\mathrm{X}$ & $\mathrm{X}$ \\
\hline
\end{tabular}




\section{Figure captions}

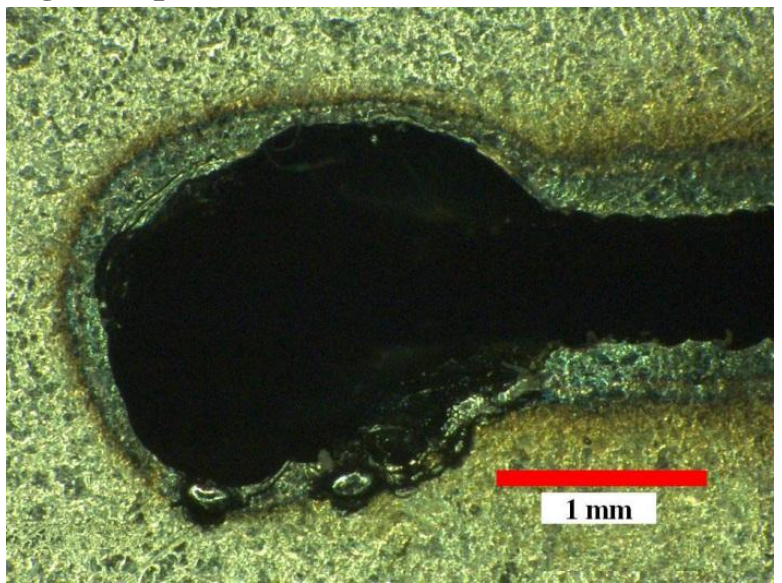

Figure 1- A pierced hole at the start of a laser cut in $2 \mathrm{~mm}$ thick mild steel using $1000 \mathrm{~W}, 2$ bar oxygen. The piercing hole is usually considerably wider than the kerf width (the kerf is shown here on the right hand side of the figure).

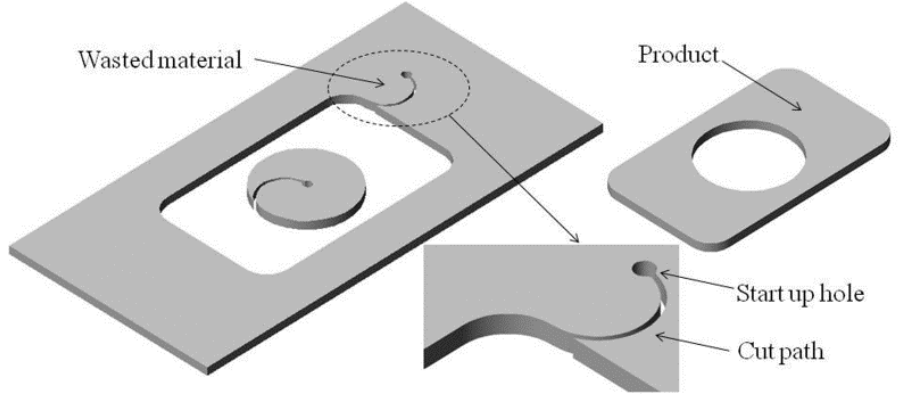

Figure 2 Illustrating how locating the initial pierced hole off of cut path wastes material and time.

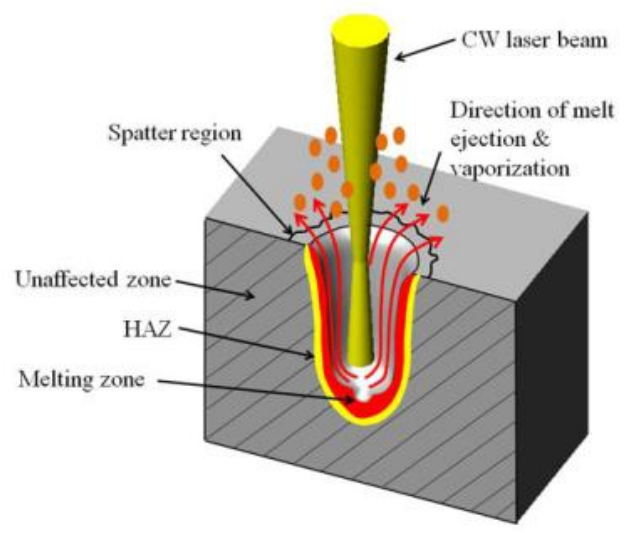

Figure 3 The laser piercing process 


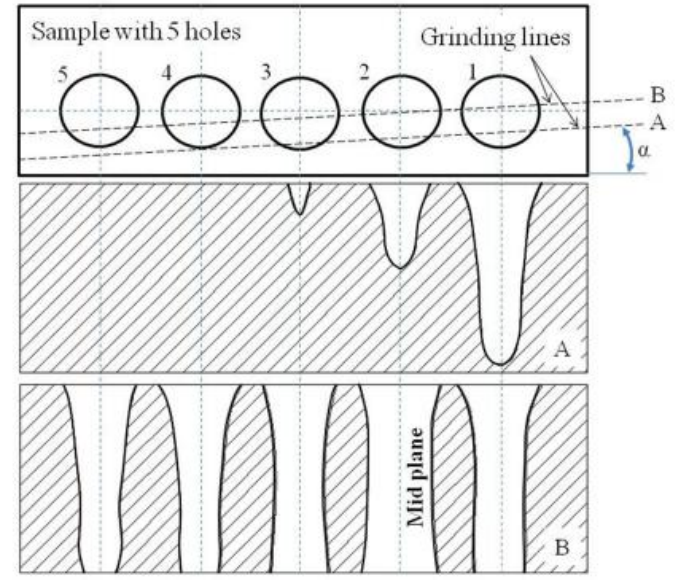

Figure 4 Schematic illustrating method used to obtain images of mid plane of holes.
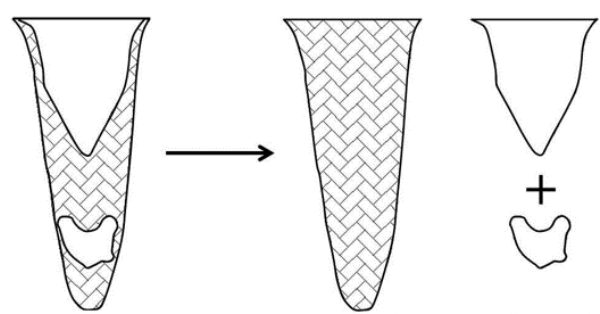

Cross section

Melted

Ejected

Figure 5- An explanation of the use of the terms melted and ejected in this work. 

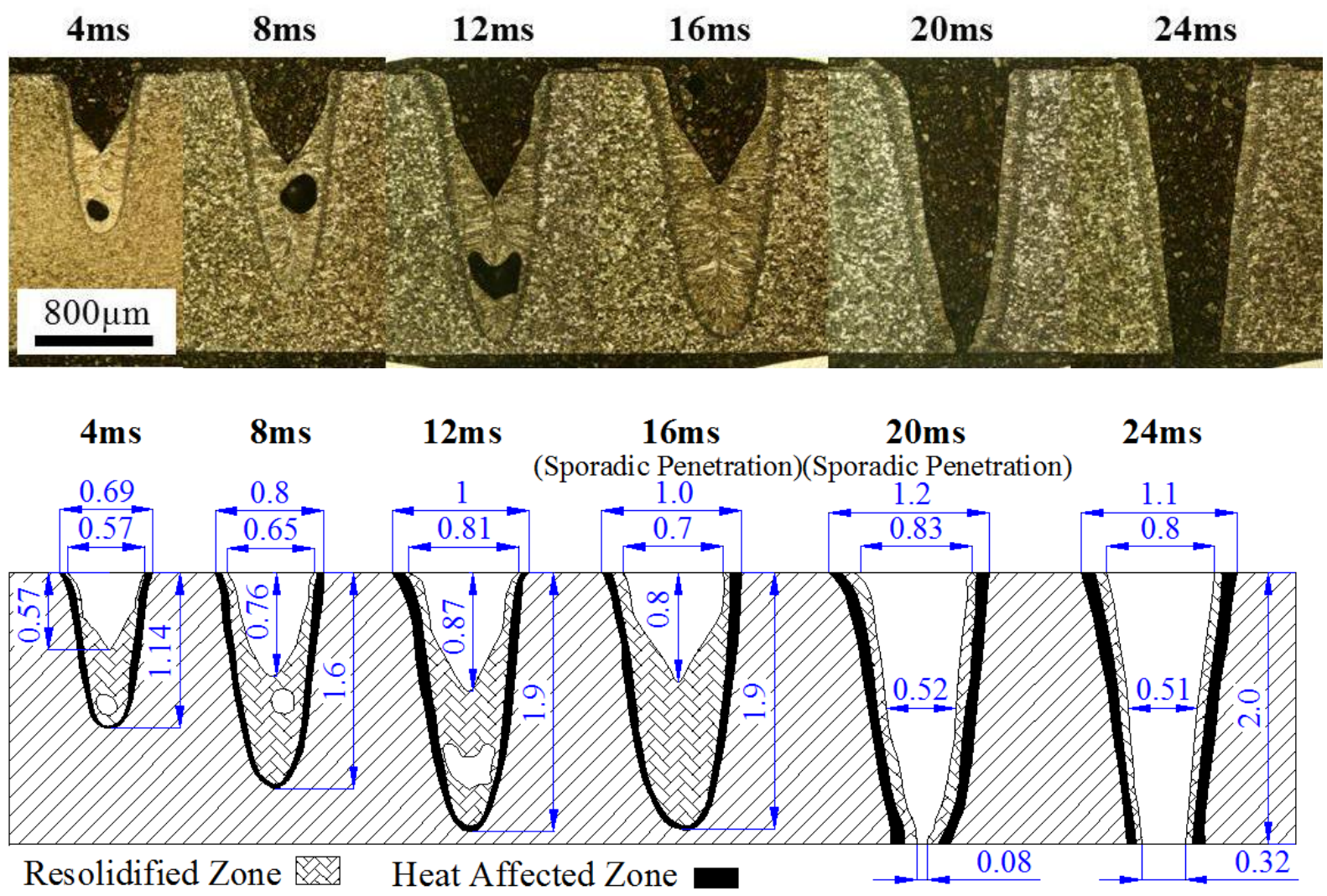

Figure 6- a. Optical micrographs b. Hole growth map showing observed hole shapes for $1000 \mathrm{~W}, 2 \mathrm{bar} \mathbf{N}_{2}$.

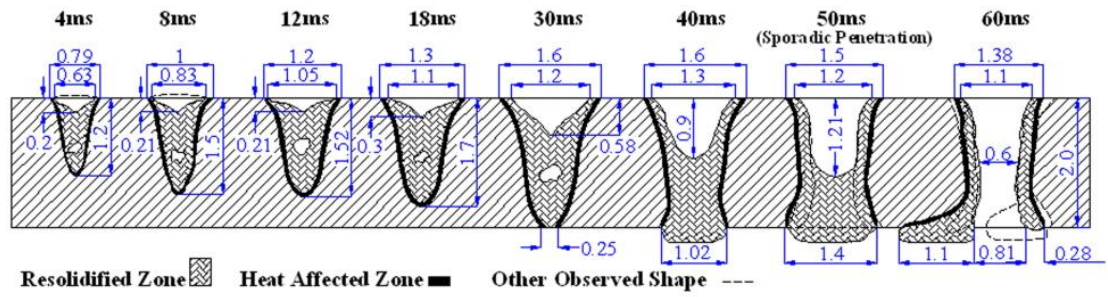

Figure 7- Hole growth map showing observed hole shapes for $1000 \mathrm{~W}, 0.3$ bar $\mathbf{N}_{2}$. 


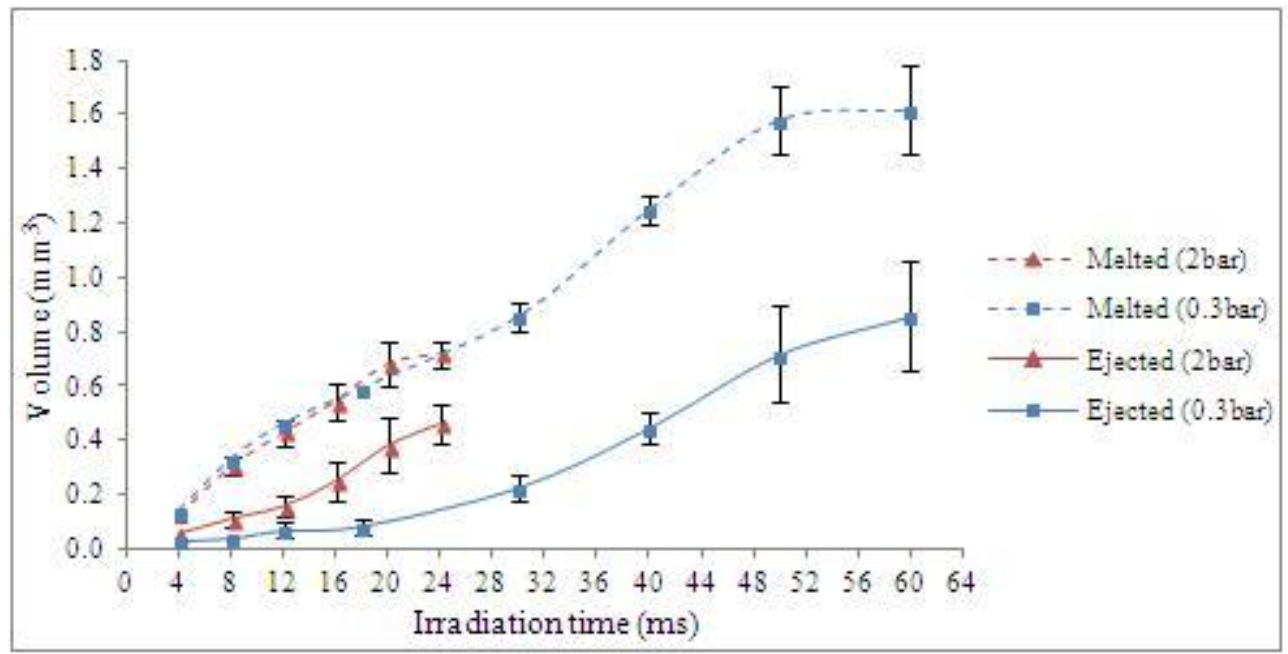

Figure 8- The volume of the melted zone and the volume of material ejected as a function of interaction time and nitrogen pressure.

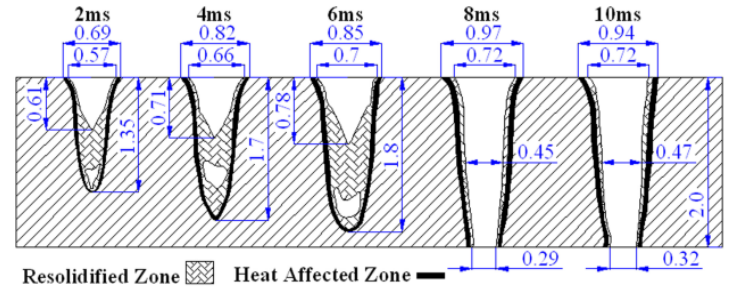

Figure 9- Hole growth map showing observed hole shapes for 1400W, $2 \mathrm{bar} \mathbf{N}_{2}$.

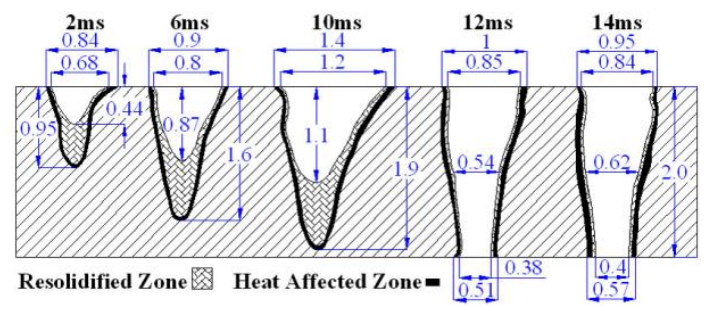

Figure 10- Hole growth map showing observed hole shapes for 1000W, 2 bar $\mathrm{O}_{2}$

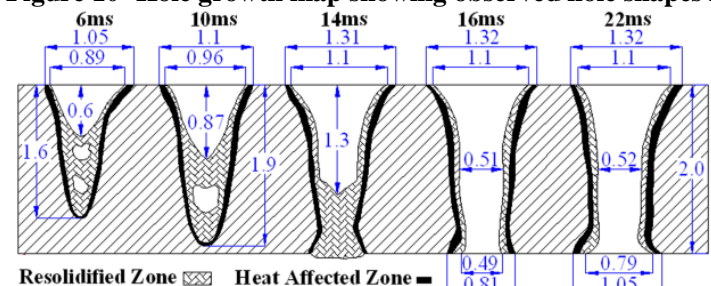

Figure 11- Hole growth map showing observed hole shapes for 1000W, 0.3bar $\mathrm{O}_{2}$. 


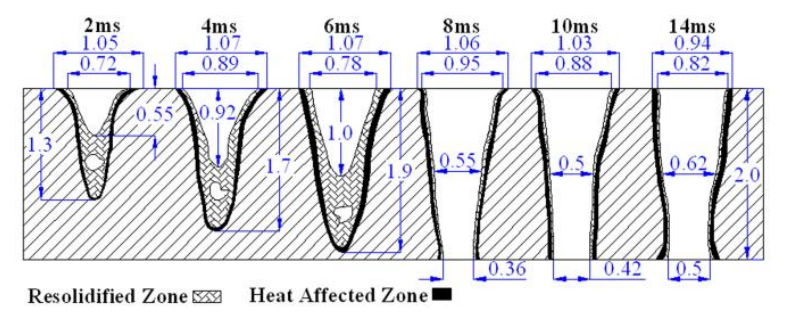

Figure 12- Hole growth map showing observed hole shapes for $1400 \mathrm{~W}, 2 \mathrm{bar} \mathrm{O}_{2}$.

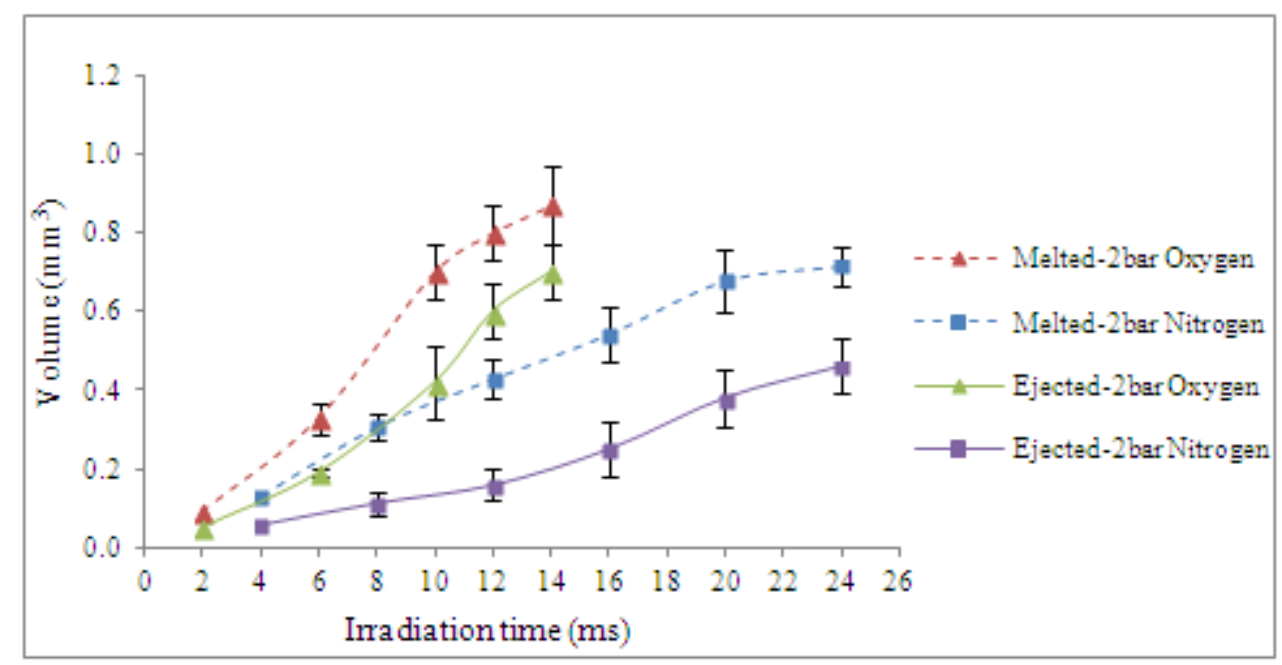

Figure 13 A comparison between oxygen and nitrogen melted and ejected volumes when piercing with $1000 \mathrm{~W}$ and 2 bar pressure.

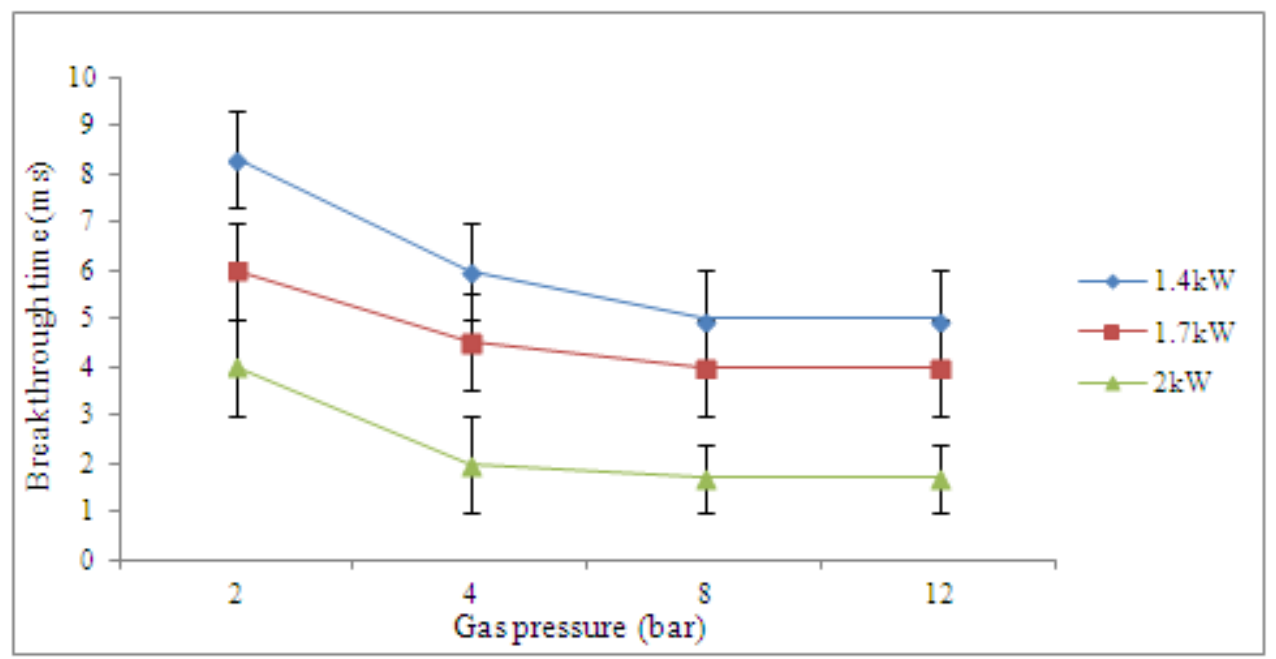

Figure 14- Pierce breakthrough times for various nitrogen pressures and laser powers (piercing times for 0.3 nitrogen were well in excess of $10 \mathrm{~ms}$ ). 


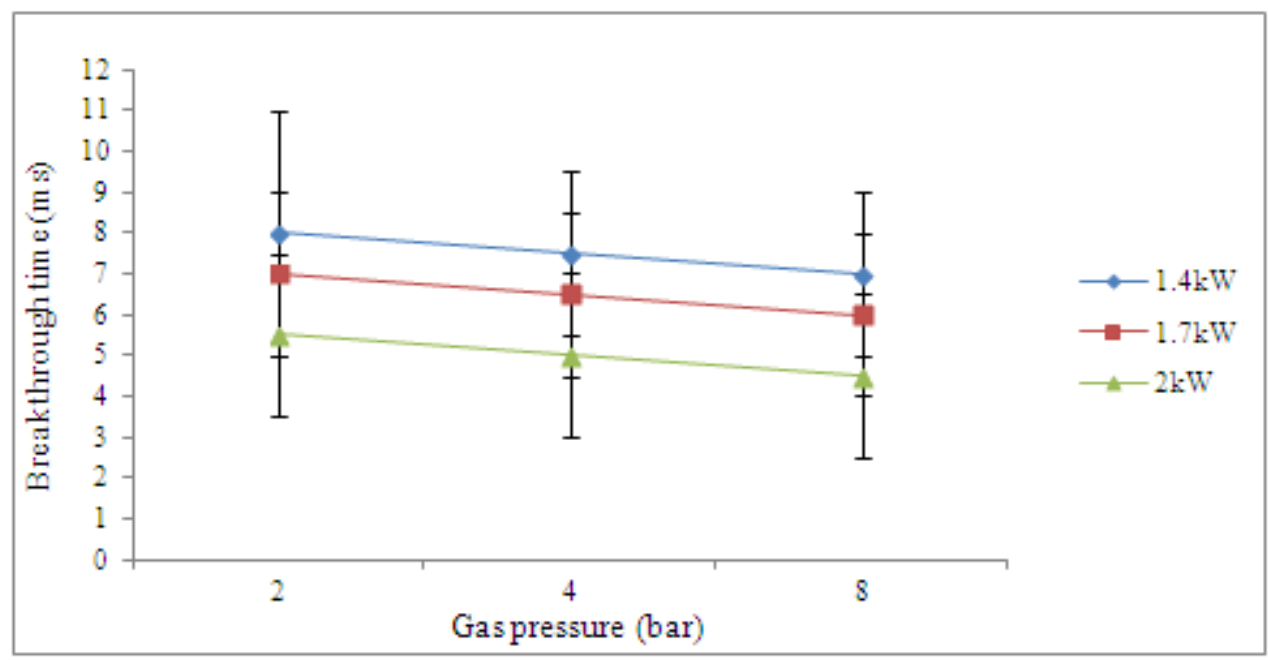

Figure 15- Pierce breakthrough times for variety of oxygen pressure and laser powers.

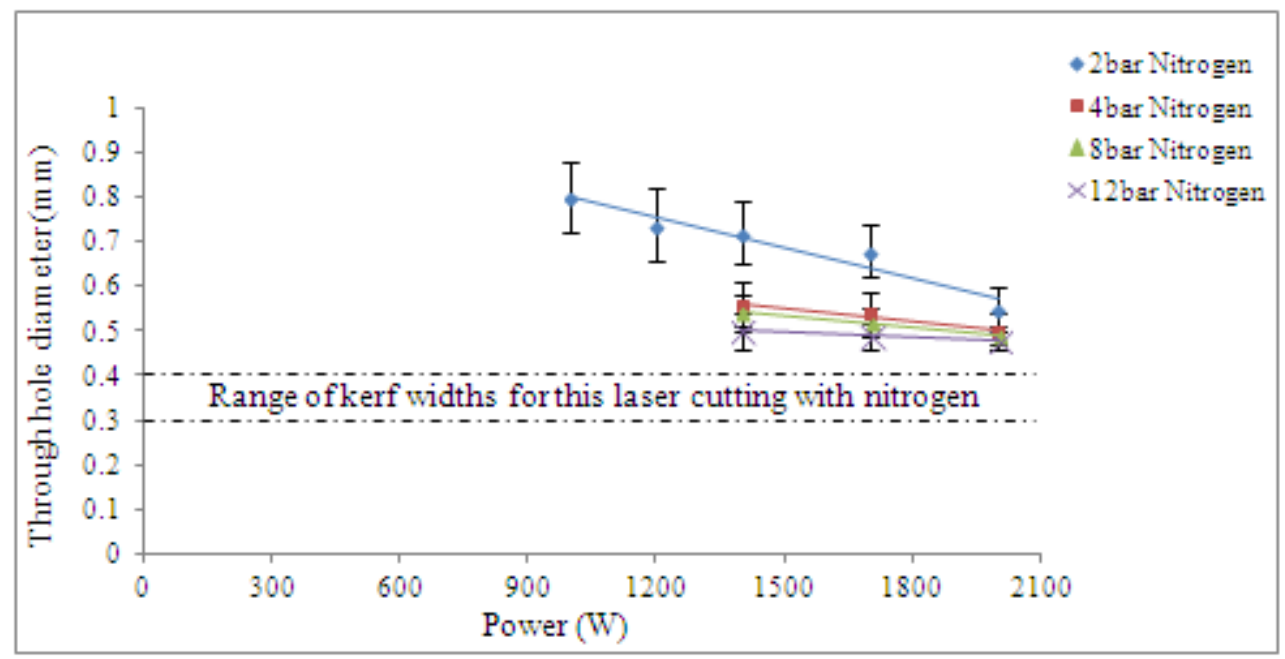

Figure 16- Upper pierce hole diameter for nitrogen at a range of powers and gas pressures. 


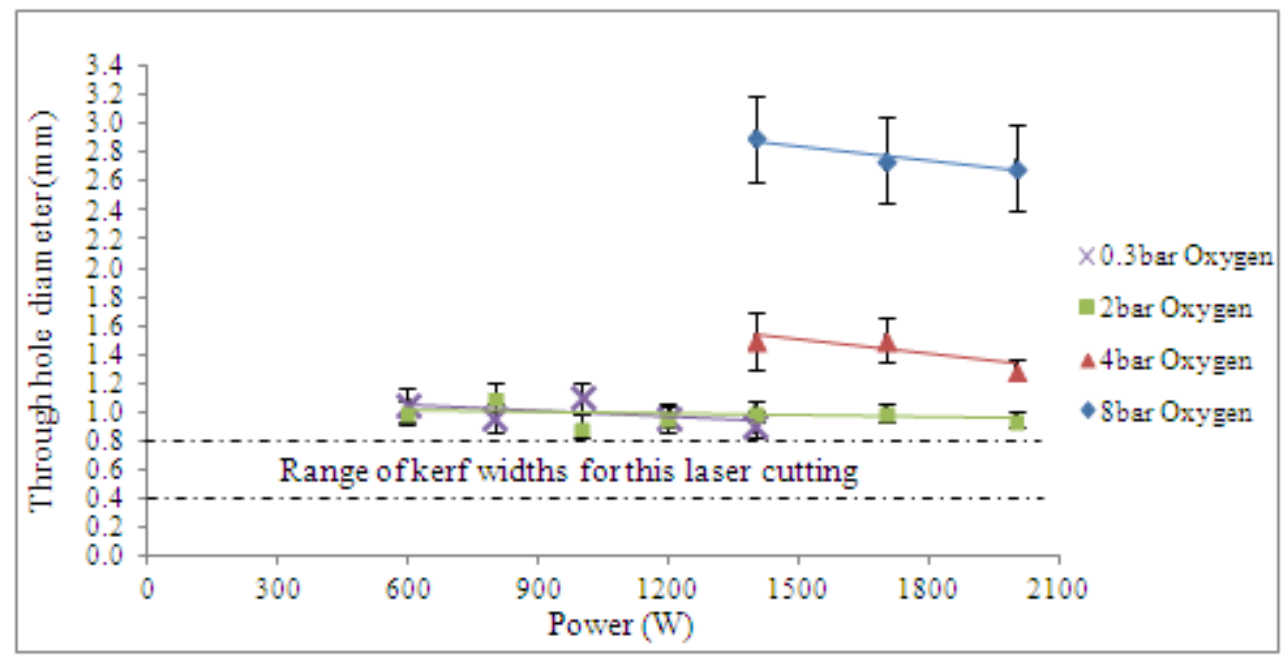

Figure 17- Upper pierce hole diameter for oxygen at a range of powers and gas pressures.

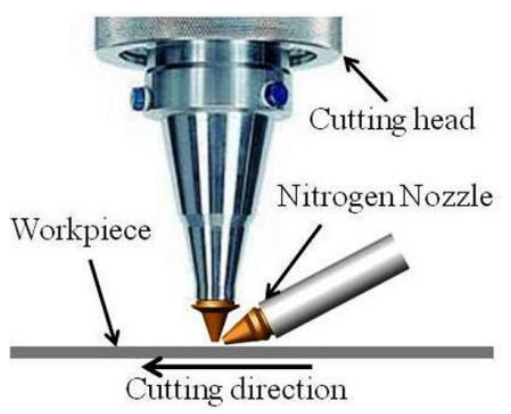

Figure 18- Indicating the set up of piercing with nitrogen-cutting with oxygen.

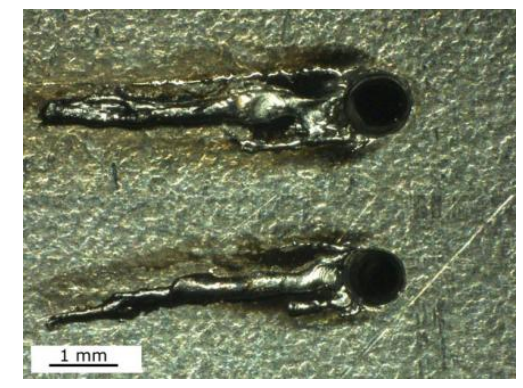

Figure 19 Showing two holes pierced using the auxiliary inclined nozzle. (3bar pressure of nitrogen, 1500W, 20ms). 


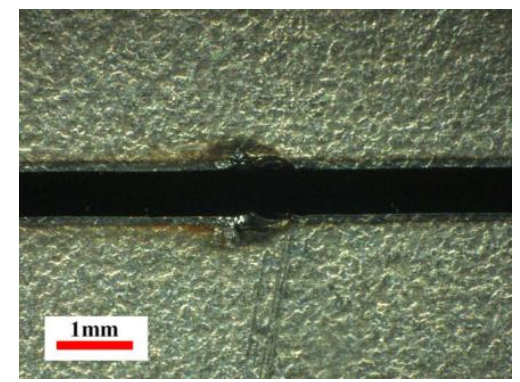

Figure 20- A hole with nitrogen was pierced at the middle of cut path before cutting by oxygen. 
References

1. Voisey, K.T., et al., Melt Ejection During Laser Drilling of Metals. Mat Sci Eng A, 2003. 356: p. 414-424.

2. Österle, W., S. Krause, T. Moelders, A. Neidel, G. Oder and J. Völker, Influence of heat treatment on microstructure and hot crack susceptibility of laser-drilled turbine blades made from Rene 80. Materials Characterization, 2008. 59: p. 1564-1571.

3. Low, D.K.Y., L. Li and A. G. Corfe, Effects of assist gas on the physical characteristics of spatter during laser percussion drilling of NIMONIC 263 alloy. Applied Surface Science, 2000. 154-155.

4. Leigh, S., K. Sezer, L. Li, C. Grafton-Reed and M. Cuttell, Statistical analysis of recast formation in laser drilled acute blind holes in CMSX-4 nickel superalloy International Journal of Advanced Manufacturing Technology, 2009. 43: p. 1094-1105.

5. Chien, W.-T. and S.-C. Hou, Investigating the recast layer formed during the laser trepan drilling of Inconel 718 using the Taguchi method. International Journal of Advanced Manufacturing Technology, 2007. 33(3-4): p. 308-316.

6. Corcoran, A., et al., The Laser Drilling of Multi-Layer Aerospace Material Systems. J Mater. Proc. Tech., 2002. 123: p. 100-106.

7. Tam S.C., C.Y.Y., S. Jana, M.W.S. Lau, E.N. Lim, L.J. Yang, Y.M. Noor, Optimization of laser deep-hole drilling of Inconel 718 using the Taguchi method. J Mater Process Technol, 1993. 37: p. 741-757.

8. Yeo CY, S.C.T., S. Jana, M.W.S Lau, A technical review of the laser drilling of aerospace material. J Mater Process Technol, 1994. 42: p. 15-49.

9. Ng G.K.L., L.L., Repeatability characteristics of laser percussion drilling of stainless-steel sheets. Opt Laser Eng, 2003. 39: p. 25-33.

10. Ghoreishi M, D.K.Y.L., L. Li, Comparative statistical analysis of hole taper and circularity in laser percussion drilling. Int J Mach Tool Manuf 2002. 42: p. 985-995.

11. Yilbas, B.S., Study of affecting parameters in laser hole drilling of sheet metals. Transactions of the ASME, 1987. 109: p. 282-287.

12. Powell, J., J. Petring, R. V. Kumar, S. O. Al-Mashikhi, A. F. H. Kaplan and K. T. Voisey, Laser-oxygen cutting of mild steel: the thermodynamics of the oxidation reaction. Journal of Physics D: Applied Physics, 2009. 42: p. 015504.

13. Schulz, W., Eppelt, U., Poprawe' R., Review on laser drilling I. Fundamentals, modeling, and simulation J. Laser Appl, 2013. 25(012006).

14. Tirumala Rao, B., M. O. Ittoop and L. M. Kukreja, A power ramped pulsed mode laser piercing technique for improved $\mathrm{CO}_{2}$ laser profile cutting. Optics and Lasers in Engineering, 2009. 47: p. 1108-1116.

15. Al-Mashikhi, S.O., Fibre laser cutting of thin section mild steel, in Faculty of Engineering. 2009, University of Nottingham.

16. Ivarson, A., J. Powell, J. Kamalu and C. Magnusson, The oxidation dynamics of laser cutting of mild-steel and the generation of striations on the cut edge. Journal of Materials Processing Technology, 1994. 40: p. 359-374.

17. Miyamoto, I.a.H.M., The mechanism of laser cutting. Welding in the World. 29: p. 283294.

18. Miyamoto, I. and H. Maruo, The mechanism of laser cutting. Welding in the World, 1991. 29: p. 283-294. 